\title{
Neuroticism and home bias
}

\author{
Pawel Niszczota \\ Poznań University of Economics and Business, \\ Department of International Finance, Poznań, Poland \\ e-mail address: pawel.niszczota@ue.poznan.pl
}

An earlier version of this paper circulated under the title Neuroticism, uncertainty and foreign investment:

Niszczota, Paweł, Neuroticism, Uncertainty, and Foreign Investment (March 31, 2014). Available at

SSRN: https://ssrn.com/abstract=2431188 or http://dx.doi.org/10.2139/ssrn.2 431188

The current version also includes an individual-level analysis. Thus, in the new version of the manuscript the analysis of neuroticism is performed on both the country level and the individual level. 


\title{
Neuroticism and home bias
}

\begin{abstract}
In this paper I investigate whether neuroticism has a negative impact on investment in foreign securities, exacerbating the 'home bias' present while investing in stocks and bonds. This hypothesis is motivated by research which: (1) established a link between neuroticism and fear of uncertainty, (2) revealed that investors feel greater uncertainty when considering investment in foreign securities, and (3) shown that negative affect impacts in-group bias. I explore this hypothesis on both the country level (using cross-country observational data) and individual level (using the responses of students that were given a hypothetical investment scenario). Additionally, I explore whether the predicted relationship is further exacerbated when uncertainty or anxiety is high, or when the investment destination is dissimilar from the investors' own country. The country-level analysis reveals that investors from high-neuroticism countries generally invest less in foreign equities than investors from other countries, and provides some support that this tendency can become more pronounced when investing in times of high uncertainty or in culturally dissimilar countries. The hypothesized relationship is also present in the responses of male students in a high-anxiety (stressful) condition. Given that professional investors are predominantly male, and work under high stress, this explains to some extent why investors have a bias towards domestic securities.
\end{abstract}

Keywords: neuroticism; personality; uncertainty; anxiety; finance; decision making JEL Classification: D81; G11; G15; G41

PsycINFO classification: 3120 


\section{Introduction}

Home bias, or the tendency of individuals to overinvest in domestic stocks (and other assets), is a well-documented phenomenon in the financial literature. This bias produces inferior outcomes (per unit of risk taken) than those that would be achieved if investors had more foreign assets in their portfolios (e.g., Solnik, 1974), as a greater presence of foreign assets in portfolios allows investors to more fully exploit the benefits of diversification (Markowitz, 1952), by utilizing the fact that the fortunes of the economy of one country are never perfectly correlated with the fortunes of the economy of another country. The purpose of this study is to assess whether neuroticism - one of five factors from the dominant model of personality (e.g., Digman, 1990) - exacerbates this tendency. This hypothesis is motivated by previous research, which established a link between neuroticism and the tendency to avoid uncertainty, revealed the way foreign securities are perceived by investors, and shown that negative affect (that neurotics are prone to) impacts in-group bias. In the case of investments, this bias should manifest itself in the preference for domestic (more familiar, 'safer') stocks or bonds.

Given that neurotics react poorly to stress and tend to feel threatened or anxious very easily, it is not surprising that they have a greater propensity to avoid situations, which have the potential to produce negative outcomes. Consequently, individuals with low levels of emotional stability (the opposite of neuroticism) exhibit fear (or low tolerance) of uncertainty and risk (Berenbaum, Bredemeier, \& Thompson, 2008; Cloniger, 2000). ${ }^{1}$ Extant research shows that neurotic individuals reveal their attitude toward uncertainty and risk both at the physiological level, and through their choices. The former point is best illustrated by the study of Hirsch and Inzlicht (2008), who have demonstrated that the brain activity of neurotic individuals shows that they react more vividly to uncertain feedback concerning their performance than to

\footnotetext{
${ }^{1}$ An indication of the importance of uncertainty in this personality dimension is provided by Cloniger (2000), who identified 'fear of uncertainty' as a facet (subscale) of the 'harm avoidance' dimension of his taxonomy of personality. This dimension corresponds to the neuroticism factor in other models of personality.
} 
negative feedback, conversely to the reactions of individuals that have low levels of neuroticism. These results encourage the authors to conclude that uncertainty for neurotics is so discomforting, that they seem to prefer 'the devil they know' (unambiguously negative information) over an uncertain outcome. Other evidence for this link can be found in analyses that focus on the trait-anxiety levels of individuals, one of the subscales (facets) of neuroticism in many models of personality. Individuals with high trait-anxiety tend to be risk-averse in a general sense (e.g., Maner et al., 2007), are more reluctant to acquire equity or debt securities, and have a greater preference for less risky portfolios than other individuals (Gambetti \& Giusberti, 2012; Bucciol \& Zarri, 2017).

In this paper, I posit that individuals that are high in neuroticism might also be reluctant to acquire foreign stocks and bonds (i.e., equity and debt securities, respectively). This is due to the way that foreign securities seem to be perceived in relation to their domestic counterparts, which reflects the notion that investors exhibit 'fear of the alien and distant' (Huberman, 2001, p. 678). One example of this is provided by Kilka and Weber (2001), who show that investors expect lower returns from foreign stocks (or seem less optimistic towards the stocks' prospects). More crucially, the same study shows that individuals perceive foreign stocks as riskier, as measured by the expected dispersion of returns. Another example is provided by Kang and Stulz (1997), whose work suggests that when investors actually decide to invest abroad, they prefer larger firms, most of which they probably already knew due to their size and presence on other markets (which made them feel less 'alien and distant'). A non-mutually exclusive explanation for why individuals high in neuroticism should be more reluctant to invest in foreign securities is that these individuals are by definition more prone to negative affect. This in turn can increase in-group bias (Forgas \& Moylan, 1991; Forgas, 1995; Wilder \& Simon, 2003), which in our case could translate into a greater preference for domestic securities (under 
the assumption that investors make at least part of their investment decisions under the influence of negative affect).

The study uses a rarely-used approach, in that it investigates the issue in question on two levels: the country level, and the individual level. The country-level investigation (made possible by the availability of cross-country investment data) attempts to look at the results of decisions made by actual investors (in contrast to studies that usually focus on the responses provided by individuals that are presented with hypothetical scenarios). This, combined with the existence of cross-cultural assessments of the mean personality profiles, allows us to test if a higher mean level of neuroticism in a given country translates into a greater degree of underinvestment in foreign securities. Such an approach is warranted, given that previous crosscultural studies of personality find that it is sensible to treat between-country scores analogously to how one would compare scores of individuals within a given country (e.g., van Hemer, van de Vijver, Poortinga, \& Georgas, 2002; McCrae et al., 2005).

However, given that some academics argue that the mean scores across countries do not correspond to actual differences, and are only the result of methodological issues (e.g., Heine, Lehman, Peng, \& Greenholtz, 2002), it seems advisable to test whether the hypothesized effect is present while investigating the investment preferences of individuals from the same culture, using the same personality inventory. Therefore, the country-level analysis is complemented by an individual-level analysis, in which university students (from one country) are asked to allocate money between foreign and domestic stocks in a hypothetical investment scenario.

Additionally, the present investigation attempts to answer whether the expected relationship becomes stronger when decisions are made in conditions which should amplify the willingness to choose domestic securities, i.e.: (1) when uncertainty (on financial markets) or anxiety (in individuals) is high, and (2) when the recipient of the investment is vastly different than the investors' own country. It is plausible that the effect of neuroticism might become present only 
in times of high uncertainty, or when individuals are in an anxious state, as this is precisely when the effect of neuroticism should manifest itself, causing a divergence in behavior between neurotic and emotionally stable individuals. Therefore, in addition to the main hypothesis, I investigate whether the effect of neuroticism is exacerbated when either uncertainty or anxiety is temporally high, or when the target of the investment greatly differs from the individuals' own country.

\section{Country-level analysis}

\subsection{Data and methodology}

\subsubsection{General procedure}

The standard approach used in the literature while performing analyses of foreign portfolio investments is to refer not to the absolute, but the relative level of investments, in which researchers compute benchmark levels of investments based on some model, such as the International Capital Asset Pricing Model (ICAPM). In this study I follow this approach, and define the dependent variable (separately for equity and debt securities, and each year used in the study) as the log ratio of the observed weight of securities from host (destination) country $j$ in the portfolio of investors from home (investor) country $i$ (in year $t$ ), to the optimal weight according to the ICAPM, that is one that corresponds to the relative size of a foreign market based solely on the market value of the securities, i.e.:

$$
y_{i j t}=\log \left(\frac{w_{i j t}}{w_{j t}^{*}}\right) \text {. }
$$

In order to compute the relative value of investment, I use the data provided by the International Monetary Fund (IMF) in the Coordinated Portfolio Investment Survey, which shows end-of-year bilateral country holdings for both equity and debt securities. The IMF has first reported such data in 1997 , and has done so in a yearly fashion since 2001 . To obtain a continuous study period, I discard observations from the first round of the survey, and 
investigate twelve years of holdings' data, from 2001 to 2012. The weight $w_{i j t}$ refers to the share of securities from country $j$ in the total value of securities held by residents of country $i$, whereas the baseline weight $\left(w^{*}{ }_{j t}\right)$ to the share of the value of securities from country $j$ in the total value of securities from all 50 host countries used in this study. Similarly to Beugelsdijk and Frijns (2010), the dependent variable is fixed at the log of 0.001 when a home country does not hold any securities from a specific host country. ${ }^{2}$

The existence of several cross-country personality assessments gives us a certain degree of freedom when choosing an appropriate form for the key independent variable: the mean neuroticism score of individuals from a specific country. In this paper I use scores that were established based on the observer-rating Revised NEO Personality Inventory (NEO-PI-R; McCrae et al., 2005) and the Eysenck Personality Questionnaire (EPQ; Eysenck \& Eysenck, 1975), which are used to extract scores that correspond to the 'Big Five' and 'Big Three' models of personality, respectively. The use of mean scores based on these inventories has been proven to be a valid way of comparing individual differences between countries, given that prior research has demonstrated that there is an equality of the factor structure at the between-country and within-country level (McCrae et al., 2005; van Hemert et al., 2002). It is worth mentioning how the NEO-PI-R scores were computed, given that the 'Big Five' is currently the dominant taxonomy. To assess how these scores might vary across the world, McCrae et al. (2005) asked college students ${ }^{3}$ from 51 cultures $(\mathrm{N}=12,156$, with a median sample size of 198 for each culture) to think of a person born in the same country as they were, and describe their personality using 240 statements (48 of them were used to assess neuroticism). Based on their

\footnotetext{
2 Although the IMF provides data for a more extensive number of countries, many potential home and host countries are excluded due to the unavailability of information on the control variables. Moreover - to ensure that the quality of the dataset will allow us to draw reliable inferences - I exclude from the analysis home country-year pairs in which IMF lists investments in less than 44 countries, and home countries for which we do not have at least 3 years of data. As a conservative measure, I also exclude investments made to and from Ireland and Luxembourg, which often serve as intermediaries in capital flows.

${ }^{3}$ In rare cases, adult samples were used.
} 
answers, aggregate factor $T$-scores (that accounted for differences in sex and age) were computed for each culture. The mean neuroticism scores in each home country (culture) used in this study are presented in the Appendix (this includes the NEO-PI-R scores, and the scores operationalized by the EPQ).

To ensure that the analysis is robust, I include a wide range of control variables in all regressions. ${ }^{4}$ Firstly, I control for Hofstede's uncertainty avoidance dimension and national wealth (to rule out that they do not make the investigated variable redundant (e.g., Hofstede \& McCrae, 2004). Secondly, I control for the general level of home bias in each home country, to more accurately estimate the individual effect of other predictors. Thirdly, regressions consider the effect of variables that proxy for the level of similarity or familiarity between the home and host country (geographic distance, bilateral trade, cultural distance, and dummies that separately account for instances when the home and host country share a common official language, religion, or have a legal system of the same origin (each variable takes the value of one when there is such a commonality). Finally, the regressions control for certain aspects of the host country's capital market that influence its' attractiveness (GDP per capita level and market capitalization to GDP ratio, market volatility, and exchange rate volatility for each host country).

\subsubsection{Possible moderators}

As mentioned earlier, it is possible that the effect of neuroticism will become more pronounced in times of high uncertainty on financial markets. A simple but effective way to test this is to compare the effect of neuroticism before and after 2008, given that September 2008 (when Lehman Brothers collapsed) serves to many as the beginning of the most recent financial crisis. The cross-country data shows end-of-year holdings, and therefore the holdings data for 2008 reflect the sea change after the September 2008 turmoil, when great amounts of

\footnotetext{
${ }^{4}$ The data sources for all the variables used in the study are reported in the Appendix.
} 
uncertainty where infused into financial markets (which one could observe through (for example) the rapid increase in the CBOE Market Volatility Index (VIX), a standard measure of market uncertainty (e.g., Bekaert, Hoerova, \& Lo Duca, 2013)).

The effect of neuroticism might also depend on the degree of similarity between the investors' own country and the investment destination, and the degree that the latter feels trustworthy or familiar. A general expectation is that the greater the differences between the two countries, the more difficult it will be for emotionally unstable individuals to invest in the securities of foreign origin. I posit that a high degree of dissimilarity between the country that a neurotic individual comes from and the country where she or he considers making an investment should elevate uncertainty (consistent with evidence of a link between unfamiliarity and perceived uncertainty provided by Hockey, Maule, Clough, and Bdzola (2000)), and exacerbate the effect of neuroticism.

The first group of potential moderators describe the cultural differences between the country making the investment and the country receiving the investment. These differences can be estimated using genetic and somatic distance, which - as Guiso, Sapienza, and Zingales (2009) argue - dig deeply into the differences between countries from a cultural stand point. While the former measure (which is sourced from Cavalli-Sforza, Menozzi, and Piazza (1994)) establishes between-country differences in DNA based on how frequently certain alleles are found in the population of each country, the latter measure (based on data from Biasutti (1954)) aggregates differences in physical traits between individuals from different countries, based on their height, the color of their skin, and the length-to-width ratio of their skulls. I also consider measures that refer to more specific aspects in which two countries can differ from one another, by utilizing the measures used by Dow and Karunaratna (2006), who have analyzed how the level of trade between two countries is the result of the differences in their language, religion, 
education level, democratic values (political freedom), and ideology (the degree of preference for socialist policies).

Secondly, I analyze whether neuroticism interacts with trust, given that it has been shown in Guiso et al. (2009) that the level of trust between inhabitants of different countries affects various forms of economic activity. It seems plausible that neuroticism will interact with the mean level of trust that investors have towards individuals from the country in which they consider investing. Intuitively, neurotic individuals seem less unlikely than the remainder of individuals to invest in the stocks or bonds originating from a country, whose citizens are generally distrusted in their own country, an argument which deserves to be tested empirically.

Thirdly, I investigate whether familiarity or non-cultural similarity between countries produces differences in the effect of neuroticism on investment in foreign securities. The first variable worth investigating is the level of trade between both countries, which undeniably helps individuals from each country to accumulate various forms of knowledge concerning the partner country. Another factor that may make a foreign country feel familiar to an investor is if the legal system of the home and host country are of the same origin (I operationalize this by constructing a dummy variable that takes the value of one when this is the case, and interact this variable with neuroticism). Also, it is possible that investors - especially neurotic ones might feel more confident while investing in countries with a similar level of economic development. I test this possibility by interacting neuroticism with the log of the difference between GDP per capita in the home and host country.

\subsection{Results}

For equity investments, the results of regressions ${ }^{5}$ - that are reported in the first four columns of Table 1 - demonstrate that the effect of neuroticism is statistically significant

\footnotetext{
${ }^{5}$ The examination of the neuroticism-investment link is performed via panel data regressions, which consider the impact of a multitude of potential predictors of international portfolio investment, and take advantage of the structure of the dataset. Further, in order to assess the impact of neuroticism in comparison with the effect of
} 
( $p<0.001$ ), and remains significant at the same level after considering the effect of uncertainty avoidance. Interestingly, the change in the effect of neuroticism differs depending on whether we base the analysis on the NEO-PI-R, or the EPQ score (to make it easier to compare their effect, both are standardized in the regressions), with an increase in the latter having a more severe (negative) effect on foreign investment. As for investment in debt securities, although the effect of neuroticism has the expected sign, in all of the cases it is not statistically significant.

Fig. 1 is meant to assess whether the effect of neuroticism is sensitive to the level of uncertainty on financial markets, by showing the size of the coefficient separately for each of the twelve years used in the study. ${ }^{6}$ The upper part of Fig. 1 - which refers to investments in foreign equities - shows that starting from 2008, the size of the effect of neuroticism suggests that the severe shock induced at the beginning of the financial crisis has left a long-lasting negative effect on the propensity of individuals from high-neuroticism countries to invest in foreign equities. The size of the effect is larger for the EPQ score than the NEO-PI-R score, which corresponds with the results presented in Table $1 .^{7}$ The effect of neuroticism on investment in foreign debt securities - which is illustrated in the lower part of Fig. 1 - shows that the effect of neuroticism is negative and statistically significant in nine years for the EPQ score, but in only three years for the NEO-PI-R score. These results are noteworthy, as they suggest that neuroticism might indeed have an effect on investment in debt securities (in contrast to the results from Table 1), and that it might have been present prior to the financial crisis (in contrast to equities).

Table 2 shows whether the effect of neuroticism is exacerbated when investing in countries that are dissimilar to the investors' own country (to conserve space and enhance readability, I

Hofstede's uncertainty avoidance dimension, I present two sets of specifications, one that excludes, and one that includes this variable.

${ }^{6}$ This allows us to adopt the more robust censored regression (Tobit) procedure.

${ }^{7}$ For equities, tests for the equality of regression coefficients (Paternoster, Brame, Mazerolle, \& Piquero, 1998) show that the size of the effect of neuroticism from 2008 onwards is significantly different $(\mathrm{p}<.05)$ from what it was in earlier years (in the vast majority (NEO-PI-R scores) or all (EPQ scores) cases). 
only report parameter estimates for the interaction term). I start by analyzing the interaction terms created by interacting neuroticism with three variables used in Guiso et al. (2009), i.e. genetic distance, somatic distance, and the level of trust that inhabitants of the home country have towards inhabitants of the host country (the results are reported in Panel A). A general observation is that there are stark differences between the results depending on whether I relate to the NEO-PI-R or EPQ neuroticism score. While neither of the interactions with the former produce results of statistical significance, the latter - in all but one case - suggest the existence of an interaction effect between neuroticism and the variables that are investigated in this panel. More specifically, the negative and statistically significant coefficient for the interaction between neuroticism and genetic (somatic) distance demonstrates that as the differences between the home country and host country get greater, either from a genetic or physical-trait perspective, the effect of neuroticism becomes stronger (this interaction effect is present for both equity and debt investments). Interestingly, the level of trust also seems to interact with neuroticism, but only for debt securities.

Genetic and somatic distance are variables that capture cultural differences in a very broad sense. In Panel B I analyze how neuroticism interacts with an alternative (broad) measure of cultural distance (which aggregates between-country differences in Hofstede's cultural dimensions), as well as how it interacts with more specific cultural distance proxies. The results seem to suggest that the greater the difference between the home and host country in regard to their languages, religion, or degree of democracy, the greater the effect of neuroticism becomes (although in a quarter of the cases, the results are statistically insignificant). For the remainder of cultural proxies, the results are either insignificant (Hofstede-based cultural distance), inconclusive (distance in ideology interacts significantly only with the NEO-PI-R measure), or unexpected (distance in education, unexpectedly, has a positive effect in two specifications). 
In Panel C I explore interactions between neuroticism and variables that proxy for the level of familiarity and non-cultural similarity between the home and host countries. Evidence of an expected interaction effect with neuroticism is present only when I relate to the commonality of the origin of both countries' legal system. The level of trade between the home and host country does not seem to have a more severe impact on the decision-making process of investors from high-neuroticism countries. Economic distance either has a positive interaction effect (equity investments) or has no significant effect (debt investments), which in the case of the former shows that high-neuroticism countries in fact prefer to invest in the stocks from countries with a dissimilar level of economic development.

\subsection{Discussion}

The results have shown that in the case of equity investments, a higher level of neuroticism - operationalized by either NEO-PI-R or EPQ - leads to a relatively lower level of investment in foreign securities, as hypothesized. However, the analysis has revealed that when using the EPQ scale of neuroticism, the results are generally stronger than when using the NEO-PI-R scale. There are two plausible reasons for these differences. Firstly, it is possible that the binary response format of the EPQ (where respondents choose between 'yes' and 'no' for each item) is better in capturing cross-cultural variation in personality than the five-point Likert scale used in the NEO-PI-R. Individuals from different countries often have specific response styles, with some cultures refraining from providing more extreme answers (Hofstede \& McCrae, 2004). It is possible that these inconsistent response styles translate into a significant bias in the estimates of neuroticism for certain cultures. ${ }^{8}$ This argument is supported by the fact that the coefficient of variation of the neuroticism score for the NEO-PI-R and EPQ scale is equal to $2.7 \%$ and $12.3 \%$, respectively, suggesting that the latter might be better in extracting variation in

\footnotetext{
${ }^{8}$ Although McCrae et al. (2005) try to control for this by using observer-ratings, it is the countrymen of the person that is being rated that are making the assessment, and thus some bias resulting from differences in response styles can still be present.
} 
neuroticism around the world. Secondly, NEO-PI-R and EPQ neuroticism ultimately differ in what they are trying to measure. Whereas EPQ is derived from the Eysenck Personality Inventory (Eysenck \& Eysenck, 1964), in which the items related to neuroticism focus heavily on anxiety (Chapman, Weiss, Barrett, \& Duberstein, 2013), neuroticism in the NEO-PI-R scale contains certain facets that might not be negatively related to the propensity to invest in foreign securities, such as self-consciousness and anger-hostility (Gambetti and Giusberti (2012) provide evidence of a positive link between anger and the preference for risky assets, albeit they use an inventory that focuses specifically on this trait). It should be noted that these two explanations are not mutually exclusive.

Depending on the estimation procedure used, the analysis provides different conclusions regarding the effect of the country having a higher mean neuroticism score on investments in debt securities (but only when using the EPQ scores), i.e. the results are insignificant in the panel regressions, but significant in the majority of cases when estimating the effect separately for each year (using the Tobit procedure). It is plausible that the smaller effect of neuroticism for debt securities is caused by the existence of another effect in the opposite direction. As investments in debt securities are generally less risky than investments in equities, (some) emotionally unstable individuals might create demand for the former. This might have the potential to weaken the effect of neuroticism, and in some way, explain the divergence in the size of the effect for equities and debt.

The study also reveals the existence of an interaction effect between neuroticism and genetic distance, somatic distance (for equity and debt investments), and trust (solely for debt investments). Although Guiso et al. (2009) used genetic and somatic differences primarily as proxies for cultural differences between countries, these measures also relate to differences in physical traits of individuals from the home and host country (more indirectly, for the former variable, and by its very definition, in the case of the latter variable). This suggests that neurotic 
individuals feel less confident when considering investments in countries inhabited by people that look differently from their countrymen and have dissimilar cultures. ${ }^{9}$ The argument that physical traits can matter in circumstances related to investment (albeit indirectly) is supported by the results provided by DeBruine (2002), who demonstrates that people seem to have greater trust in people that are similar to them.

\section{Individual-level analysis}

\subsection{Data and methodology}

\subsubsection{General procedure}

In the individual-level study, participants completed a short survey containing a vignette that was printed on a single sheet of paper. On the first side of the sheet, participants provided basic demographic data, filled out the Polish version of the Ten Item Personality Inventory (Gosling, Rentfrow, Swann, 2003; Sorokowska, Słowińska, Zbieg, \& Sorokowski, 2014), and assessed their general risk preference (Dohmen et al., 2011). The Ten Item Personality Inventory provides a score for each of the 'Big Five' factors. To compute the neuroticism score $^{10}$, participants indicated how much they agreed with the statement that they are "anxious, easily upset", and "calm, emotionally stable", on a scale of 1 (disagree strongly) to 7 (agree strongly); the former item was reverse-coded. The second side of the sheet contained the following vignette:

Imagine that your relative has left you 30000 zloty $^{11}$ in his will. As he wanted to interest you in the world of finance, in the will he stated that you cannot withdraw this money straight away. Instead, according to the will, you have to invest the money in the stocks of

\footnotetext{
${ }^{9}$ It is likely that this only reflects greater endophilia (favoring people that are similar to us), and not greater exophobia (discriminating people that are different than us), consistent with what was found in Feld, Salamanca, and Hamermesh (2016) who introduced these terms.

${ }^{10}$ To remain consistent with the country-level analysis, emotional stability scores (that are normally produced by the Ten Item Personality Inventory) were recoded to reflect neuroticism scores.

${ }^{11}$ This is equivalent to about 7,500 USD, and the median annual net income in Poland at the time when the study was carried out.
} 
companies chosen by you, and the money invested this way can be withdrawn no earlier than 5 years from now (if you decide to sell the stocks then).

Having not much choice, you decide to contact your friend who has a lot of experience in investing. His suggestion is to invest in stock funds. However, he recommends that you should invest not only in stock funds that invest exclusively in companies from Poland, but also in stock funds that invest in foreign companies that have a similar expected return and level of risk as companies from Poland. Your friend points out that although investing in such "foreign" stock funds (that invest only in foreign companies) would likely give you a similar profit (for a similar level of risk taken) as investing in a "domestic" stock fund (that invests only in Polish companies), it is recommended nonetheless (according to the rule: "do not put all your eggs in one basket").

Being in this situation, indicate what percentage of your inheritance you would invest in the Polish stocks, and what percentage in the foreign stocks.

After giving their answer, participants rated their level of understanding of the problem on a scale of 1 (not understood at all) to 5 (completely understood).

The majority of participants completed a longer version of the survey, that contained an additional question: participants were asked in which two countries they would make an investment, if they could only select from the six countries listed. The list was designed to include three 'close' (culturally similar, familiar) and three 'distant' (culturally dissimilar, less familiar) investment destinations. The initial selection of countries that would meet these criteria was based on how much liked or disliked citizens of each country were in the country in which the study was performed (Centrum Badania Opinii Społecznej, 2016). Such an approach is warranted, given that investors seem to choose investment destinations based on how they feel about each country, a heuristic which generally reflects the various forms of cultural distance between their own country and another country (Hwang, 2011). The final list 
of countries was selected so that each one of them was matched as closely as possible to the participants' own country in terms of risk and expected return of stocks, as well as the size and level of development of the economy. To investigate country choice, an 'Investment in distant countries' variable was created, that equaled 1 when both selected countries were distant (unpopular) countries, -1 when both selected countries were close (popular) countries, and 0 otherwise.

The study was conducted between May and July 2016. Four-hundred and eighty-six students from two Polish universities completed the survey. Thirty-three participants were excluded from the study, as they stated that Polish was not their native language, failed to provide key information, or provided answers that suggested that they misunderstood the instructions or responded maliciously. The final sample consists of 453 participants (mean age $=21.9$ years, $S D=1.7)$. It must be noted that the vast majority of the participants $(81 \%)$ were female, which sharply contrasts with the gender composition of individual investors (for example, in Barber and Odean's (2001) dataset, 79\% of individual investors are male). Thirtyfour percent of the participants were pursuing a finance-related degree, $27 \%$ a degree in economics or management, $15 \%$ a degree in psychology, and the remaining $24 \%$ a degree in a different area. The Cronbach's alpha of the neuroticism score was equal to .69 , similar to the internal consistency obtained in the original study on this personality inventory and its Polish adaptation (.72-.73). Participants reported a good understanding of the task (mean level of understanding $=4.03, S D=1.01)$.

\subsubsection{Possible moderators}

To make it possible to investigate whether the potential effect of neuroticism is different when individuals are in an anxious state, $16 \%$ of the participants completed the survey in the 
high-anxiety (stressful) condition. Instead of inducing stress and anxiety ${ }^{12}$ in participants via some standard procedure (e.g., Kirschbaum, Pirke, \& Hellhammer, 1993), participants in the high-anxiety condition were asked to complete the survey prior to taking a mid or end-term course examination, or prior to defending their Bachelor's thesis. ${ }^{13}$ In essence, this part of the study constituted a natural experiment, with participants not under the influence of anticipatory stress serving as controls. ${ }^{14}$ The advantage of using real-life stressors is that they are most likely superior to laboratory stressors if one is interested in investigating individual differences (Kajantie \& Phillips, 2005). To some extent this mirrors the procedure applied above in the country-level analysis. However, instead of looking whether the negative effect of neuroticism on foreign portfolio investment is magnified in times when uncertainty is high, we can investigate whether individuals that are temporarily anxious have a higher tendency to choose domestic securities, and securities from countries that are similar to their own country. This corresponds to the escalation of the preference for familiarity (an increase in neophobia) under stress, that was documented in animal research (Litt, Reich, Maymin, \& Shiv, 2011).

The divergence between the gender composition of the study's participants and actual investors in itself warrants taking a closer look at possible differences between the behavior of males in females via a subsample analysis. However, the other reason for doing so is that men show greater reactivity to acute psychological stress related to achievement challenges such as examinations (Stroud, Salovey, \& Epel, 2002; Frankenhaeuser et al., 1978). This is consistent with the well-established effect showing that activation of the hypothalamic-pituitaryadrenocortical (HPA) axis (a stress-responsive neuroendocrine system) and cortisol secretion

\footnotetext{
${ }^{12}$ I assume that (anticipatory) stress leads to feelings of anxiety (consistent with, e.g., Al'Absi et al. (1997) and Birckett (2011)).

${ }^{13}$ A small number of participants politely declined to participate in the study, stating that they were currently under too much stress. It is later discussed how this could have potentially impacted the results.

${ }^{14}$ A somewhat similar procedure is found in Preston, Buchanan, Stansfield, and Bechara (2007) and Starcke, Wolf, Markowitsch, and Brand (2008), where participants performed a gambling task while anticipating a stressful speech.
} 
(the product of HPA activity) following exposure to psychological stress is greater in males than in females (Kudielka \& Kirschbaum, 2005; Kudielka, Hellhammer, \& Wüst, 2009). Moreover, several studies have shown that the link between neuroticism and the HPA system's activity is stronger in males than in females (Oswald et al, 2006; Zobel et al., 2014; DeSoto \& Salinas, 2015).

To efficiently investigate whether the effect of neuroticism is different when being in an anxious state, all specifications contain 'Neuroticism' as a single term (that shows its effect in normal circumstances) and a 'Neuroticism x High-anxiety condition' interaction term (that shows how the effect differs when participants were in an anxious state). Neuroticism scores are centered, and thus the coefficient for 'High-anxiety condition' states the effect of being in an anxious state for a participant with a mean level of neuroticism. To control for participants' risk tolerance and expected investment knowledge, all specifications include a risk tolerance variable and a dummy variable that equals one if a participant majors in economics, finance, or management. It is also appropriate to control for gender (in the full sample regressions), one reason being that there seems to be stronger in-group bias in men than women (e.g., Sidanius, Levin, Liu, \& Pratto, 2000), which could translate into different response patterns.

\subsection{Results}

Table 3 presents the results of a regression analysis showing the impact of neuroticism in the individual-level study. To minimize the influence of two outliers in the dataset - and increase the robustness of the findings - I simultaneously investigate: (1) OLS regressions in which these outliers are excluded, and (2) robust regressions.

Regressions made on the full sample suggest that in normal circumstances, neuroticism has no effect on allocations, and that this effect is not significantly different in the high-anxiety condition. However, a subsample analysis shows that in the high-anxiety condition, this result was largely determined by differences in the response patterns of male and female participants. 
Whereas being in an anxious state did not significantly moderate the effect of neuroticism for female participants, it did change the effect of neuroticism for male participants: for males, the 'Neuroticism x High-anxiety condition' interaction term suggests that a one-point increase in the neuroticism score reduces the allocation in foreign stocks by $4.0-4.7 \%$. Somewhat surprisingly, participants with a mean neuroticism score allocated more of their hypothetical funds in foreign stocks in the high-anxiety condition than participants in the normal condition (based on the coefficient for 'High-anxiety condition'). Although estimates obtained on the female participant subsample suggest a positive relationship between neuroticism and allocation in foreign stocks, and an exacerbation of this relationship in the high-anxiety condition, neither of these relationships is statistically significant.

The interaction between neuroticism and the high-anxiety condition is illustrated in Fig. 2, which shows - separately for male and female participants - the predicted level of allocation in foreign stocks, depending on the level of neuroticism and the condition in which participants completed the survey (the normal condition or the high-anxiety condition). Comparing extreme neuroticism scores, there is a fairly large difference in the outcomes of male participants in the stressful state. Those with a lowest possible level of neuroticism (a score of 1) would, according to estimates, allocate $62.1 \%$ of their hypothetical inheritance in foreign stocks, compared to the $37.5 \%$ that would be allocated by those with a highest possible level of neuroticism (a score of 7). ${ }^{15}$ The effect of neuroticism in the remainder of cases is relatively minor, and not statistically significant (accordingly to the results presented in Table 3).

The investigation of the relationship between neuroticism and the choice of investment destinations (not tabulated) did not show a significant effect of the former on the latter.

\footnotetext{
15 A three-way interaction shows that in the high-anxiety condition, the effect of neuroticism on the level of allocation is significantly different for males and females $(\mathrm{p}<.05)$.
} 


\subsection{Discussion}

The results of the individual-level analysis are consistent with the results of the countrylevel analysis, but only to a limited extent. Crucially, the subset of individuals in which variation in neuroticism does play a role corresponds well to the gender of most investors, and the conditions in which they make decisions. Nonetheless, it is worth discussing why this effect was not universal. The results suggest that neuroticism has no effect on the choice between domestic and foreign assets in normal conditions, i.e. when participants are not in an anxious state (under stress). A simple explanation is that for some participants the problem might have seemed too abstract, and caused them to respond in a way that did not necessarily reflect how they would behave if a similar situation were to arise in real-life (e.g., if a financial-adviser asked them to make an analogous allocation of their own money). Also, the effect might be underestimated in the high-anxiety condition, since a small number of the students approached prior to their Bachelors exam declined to participate in the study, stating that they were too anxious to participate. It is plausible that the participants that declined to participate were highly neurotic. If this was true, and there was also a monotonic (positive) relationship between neuroticism and home bias (under stress), this would have adversely affected the size of the effect.

It is also worth discussing the lack of evidence on the effect of neuroticism on the choice of investment destinations. The insignificant effect might reflect the fact that the bias of neurotic individuals towards domestic stocks (relative to foreign stocks) is stronger than their bias towards close countries (relative to distant countries), which would make it even more difficult to demonstrate a significant effect. Alternatively, the study's participants might not have as strong an affinity towards certain countries as the general population, whose sentiments determined the initial choice of investment destinations. If this were the case, this could also 
alter how each country was evaluated in terms of its perceived riskiness, in accordance with the affect heuristic (e.g., Slovic \& Peters, 2006).

\section{Conclusions}

The purpose of this study was to investigate whether higher neuroticism translates into a decreased propensity to invest in foreign securities. To increase the breadth and robustness of the findings, the analysis was performed on both the country and individual level.

The country-level analysis was made possible by the existence of cross-country data on bilateral holdings in equity and debt securities. This analysis attempted to determine whether a higher mean neuroticism score of individuals from a given country translates into lower investments in foreign securities made from that country. ${ }^{16}$ Results of this study suggest that, in general, as the mean level of neuroticism rises, the level of investment in a host country (relative to a benchmark) falls, even after considering the role of the uncertainty avoidance cultural dimension (which demonstrates that neuroticism possesses incremental validity over this measure). The magnitude and significance of this effect, however, is not uniform across specifications, and varies depending on the personality inventory the analysis is based on, being more pronounced when using the Eysenck Personality Questionnaire score rather than the Revised NEO Personality Inventory scale, and for foreign investments in equity rather than debt. The effect of neuroticism appears to be more pronounced when investigating data from 2008 upwards (i.e., after the onset of the financial crisis, which infused enormous amounts of uncertainty into financial markets), which is consistent with the notion that an aversion towards uncertainty is one of the drivers of the effect of neuroticism on home bias. A finding which is

\footnotetext{
${ }^{16}$ The analysis is valid if either: (1) the personality profiles of investors are similar to the personality profiles of the general population (consistent with the findings of Lo, Repin, and Steenbarger (2005)), or (2) investors differ from the general population, but do so in a consistent fashion way in every country. Although the findings of Fenton O'Creevy, Nicholson, Soane, and Willman (2004) suggest that finance professionals might be slightly more neurotic than other people, if the difference is the same in every country (i.e., the mean scores of investors could be presented as a linear transformation of the mean scores of the general population), than the conclusions made in this study would be unaffected.
} 
also consistent with this interpretation is that the effect of neuroticism is increased while investing in culturally distant or less familiar countries, although it must be pointed out that the evidence is not unequivocal. Thus, this study provides limited evidence that the less a country resembles the investors' own country (the less familiar it feels), the less likely it is that a neurotic investor will invest in that country.

The individual-level analysis - which complemented the country-level analysis - yielded no evidence that neuroticism has an effect on the domestic-foreign composition of stocks in normal circumstances, i.e. when one in an anxious state (under stress), regardless of gender. However, for male participants under stress, a greater neuroticism score translated into a reduction in the level of allocation in foreign stocks, and thus caused greater home bias. The results partially support previous findings that have shown greater susceptibility to in-group bias in males (Hewstone, Rubin, \& Willis, 2002), by suggesting that for male neurotics there is an increase in home bias (which could be considered a manifestation of ingroup-bias in the financial realm) under acute psychological stress. What is noteworthy is that, considering that around $80 \%$ to $90 \%$ of individuals that actively invest in securities are male ${ }^{17}$, and the fact that investors work under great stress (e.g., Oberlechner \& Nimgade, 2005), the results of both analyses are essentially consistent. Thus, this study generally supports the notion that the investment and saving patterns we might observe at the aggregate and individual level can be the result of variation in personality, contributing to a growing literature (e.g., Nyhus \& Webley, 2001; Brown \& Taylor, 2014; Niszczota, 2014; Oehler, Wendt, Wedlich, \& Horn, 2017).

Future investigations of the link between individual differences in personality and financial decision-making could address (or be cognizant of) some of the limitations of this study. For example, the individual-level study utilizes a brief inventory, where neuroticism is assessed using only two items. To achieve greater accuracy, future research could use finer, yet still

\footnotetext{
17 The proportion of males is more pronounced for fund managers (e.g., Bär, Kempf, \& Ruenzi, 2011) than individual investors (e.g., Barber \& Odean, 2001).
} 
relatively brief instruments (e.g., the Big Five Inventory (John \& Srivastava, 1999), which uses eight items to assess neuroticism). Also, the individual-level study was based on a convenience sample, and thus it would be advisable if later studies focused on actual investors (ideally from two or more different countries, which would make it possible to investigate whether the effect is independent of culture). Alternatively, to better understand investment behavior in typical conditions, future researchers could induce uncertainty or stress in participants in laboratory conditions (e.g., Buhr \& Dugas, 2009; Mosca, Lauriola, \& Carleton, 2016). 
Acknowledgments: I'd like to thank Tommy Gärling, Philip Corr, Krzysztof Przybyszewski, and Karol Klimczak for fruitful discussions and comments on the manuscript. I'd also like to thank participants of the 2014 Behavioural Finance Working Group conference, the 2017 International Society for the Study of Individual Differences conference, and the 2017 Subjective Probability, Utility and Decision Making conference for their remarks on this work. 


\section{References}

Al'Absi, M., Bongard, S., Buchanan, T., Pincomb, G. A., Licinio, J., \& Lovallo, W. R. (1997). Cardiovascular and neuroendocrine adjustment to public speaking and mental arithmetic stressors. Psychophysiology, 34(3), 266-275. https://doi.org/10.1111/j.14698986.1997.tb02397.x

Baker, S. R., \& Bloom, N. (2013). Does Uncertainty Reduce Growth? Using Disasters as Natural Experiments (Working Paper No. 19475). National Bureau of Economic Research. Pobrano z http://www.nber.org/papers/w19475

Bär, M., Kempf, A., \& Ruenzi, S. (2011). Is a Team Different from the Sum of its Parts? Evidence from Mutual Fund Managers. Review of Finance, 15(2), 359-396. https://doi.org/10.1093/rof/rfq014

Barber, B. M., \& Odean, T. (2001). Boys Will Be Boys: Gender, Overconfidence, and Common Stock Investment. Quarterly Journal of Economics, 116(1), 261-292.

Bekaert, G., Hoerova, M., \& Lo Duca, M. (2013). Risk, uncertainty and monetary policy. Journal of Monetary Economics, 60(7), 771-788. https://doi.org/10.1016/j.jmoneco.2013.06.003

Berenbaum, H., Bredemeier, K., \& Thompson, R. J. (2008). Intolerance of uncertainty: Exploring its dimensionality and associations with need for cognitive closure, psychopathology, and personality. Journal of Anxiety Disorders, 22(1), 117-125. https://doi.org/10.1016/j.janxdis.2007.01.004

Beugelsdijk, S., \& Frijns, B. (2010). A cultural explanation of the foreign bias in international asset allocation. Journal of Banking \& Finance, 34(9), 2121-2131. https://doi.org/10.1016/j.jbankfin.2010.01.020

Biasutti, R. (1954). Le Razze e i popoli della terra: Europe, Asia. Volume secondo. Unione tipografico-editrice torinese. 
Birkett, M. A. (2011). The Trier Social Stress Test Protocol for Inducing Psychological Stress. Journal of Visualized Experiments : JoVE, (56). https://doi.org/10.3791/3238

Bucciol, A., \& Zarri, L. (2017). Do personality traits influence investors' portfolios? Journal of Behavioral and Experimental Economics, 68(Supplement C), 1-12. https://doi.org/10.1016/j.socec.2017.03.001

Buhr, K., \& Dugas, M. J. (2009). The role of fear of anxiety and intolerance of uncertainty in worry: An experimental manipulation. Behaviour Research and Therapy, 47(3), 215223. https://doi.org/10.1016/j.brat.2008.12.004

Cavalli-Sforza, L. L., Menozzi, P., \& Piazza, A. (1994). The History and Geography of Human Genes. Princeton University Press.

Centrum Badania Opinii Społecznej. (2016). Stosunek do innych narodów. Warszawa: Fundacja Centrum Badania Opinii Społecznej. http://www.cbos.pl/SPISKOM.POL/2016/K_053_16.PDF

Chapman, B. P., Weiss, A., Barrett, P., \& Duberstein, P. (2013). Hierarchical structure of the Eysenck Personality Inventory in a large population sample: Goldberg's trait-tier mapping procedure. Personality and Individual Differences, 54(4), 479-484. https://doi.org/10.1016/j.paid.2012.09.024

Cloninger, C. R. (2000). A Practical Way to Diagnosis Personality Disorder: A Proposal. Journal of Personality Disorders, 14(2), 99-108. https://doi.org/10.1521/pedi.2000.14.2.99

DeBruine, L. M. (2002). Facial resemblance enhances trust. Proceedings of the Royal Society of London. Series B: Biological Sciences, 269(1498), 1307-1312. https://doi.org/10.1098/rspb.2002.2034 
DeSoto, M. C., \& Salinas, M. (2015). Neuroticism and cortisol: The importance of checking for sex differences. Psychoneuroendocrinology, 62, 174-179. https://doi.org/10.1016/j.psyneuen.2015.07.608

Digman, J. M. (1990). Personality Structure: Emergence of the Five-Factor Model. Annual Review of Psychology, 41(1), 417-440.

https://doi.org/10.1146/annurev.ps.41.020190.002221

Dohmen, T., Falk, A., Huffman, D., Sunde, U., Schupp, J., \& Wagner, G. G. (2011). Individual Risk Attitudes: Measurement, Determinants, and Behavioral Consequences. Journal of the European Economic Association, 9(3), 522-550. https://doi.org/10.1111/j.1542-4774.2011.01015.x

Dow, D., \& Karunaratna, A. (2006). Developing a multidimensional instrument to measure psychic distance stimuli. Journal of International Business Studies, 37(5), 578-602. https://doi.org/10.1057/palgrave.jibs.8400221

Eysenck, H. J., \& Eysenck, S. B. G. (1964). Manual of the Eysenck Personality Inventory. University of London Press.

Eysenck, H. J., \& Eysenck, S. B. G. (1975). Manual of the Eysenck Personality Questionnaire. London: Hodder and Stoughton.

Feld, J., Salamanca, N., \& Hamermesh, D. S. (2016). Endophilia or Exophobia: Beyond Discrimination. The Economic Journal, 126(594), 1503-1527. https://doi.org/10.1111/ecoj.12289

Fenton-O'Creevy, M., Nicholson, N., Soane, E., \& Willman, P. (2004). Traders: risks, decisions and management in financial markets. Oxford, UK: Oxford University Press. Fidora, M., Fratzscher, M., \& Thimann, C. (2007). Home bias in global bond and equity markets: The role of real exchange rate volatility. Journal of International Money and Finance, 26(4), 631-655. https://doi.org/10.1016/j.jimonfin.2007.03.002 
Forgas, J. P. (1995). Mood and judgment: The affect infusion model (AIM). Psychological Bulletin, 117(1), 39-66. https://doi.org/10.1037/0033-2909.117.1.39

Forgas, J. P., \& Moylan, S. J. (1991). Affective influences on stereotype judgements. Cognition and Emotion, 5(5-6), 379-395. https://doi.org/10.1080/02699939108411049

Frankenhaeuser, M., von Wright, M. R., Collins, A., von Wright, J., Sedvall, G., \& Swahn, C. G. (1978). Sex differences in psychoneuroendocrine reactions to examination stress. Psychosomatic Medicine, 40(4), 334-343.

Gambetti, E., \& Giusberti, F. (2012). The effect of anger and anxiety traits on investment decisions. Journal of Economic Psychology, 33(6), 1059-1069. https://doi.org/10.1016/j.joep.2012.07.001

Gosling, S. D., Rentfrow, P. J., \& Swann Jr., W. B. (2003). A very brief measure of the BigFive personality domains. Journal of Research in Personality, 37(6), 504-528. https://doi.org/10.1016/S0092-6566(03)00046-1

Guiso, L., Sapienza, P., \& Zingales, L. (2009). Cultural Biases in Economic Exchange? Quarterly Journal of Economics, 124(3), 1095-1131. https://doi.org/10.1162/qjec.2009.124.3.1095

Heine, S. J., Lehman, D. R., Peng, K., \& Greenholtz, J. (2002). What's wrong with crosscultural comparisons of subjective Likert scales?: The reference-group effect. Journal of Personality and Social Psychology, 82(6), 903-918. https://doi.org/10.1037/00223514.82.6.903

Hewstone, M., Rubin, M., \& Willis, H. (2002). Intergroup Bias. Annual Review of Psychology, 53(1), 575-604. https://doi.org/10.1146/annurev.psych.53.100901.135109

Hirsh, J. B., \& Inzlicht, M. (2008). The Devil You Know Neuroticism Predicts Neural Response to Uncertainty. Psychological Science, 19(10), 962-967. https://doi.org/10.1111/j.1467-9280.2008.02183.x 
Hockey, G. R. J., Maule, A. J., Clough, P. J., \& Bdzola, L. (2000). Effects of negative mood states on risk in everyday decision making. Cognition \& Emotion, 14(6), 823-855. https://doi.org/10.1080/02699930050156654

Hofstede, G., \& McCrae, R. R. (2004). Personality and Culture Revisited: Linking Traits and Dimensions of Culture. Cross-Cultural Research, 38(1), 52-88. https://doi.org/10.1177/1069397103259443

Huberman, G. (2001). Familiarity Breeds Investment. The Review of Financial Studies, 14(3), 659-680. https://doi.org/10.1093/rfs/14.3.659

John, O. P., \& Srivastava, S. (1999). The Big Five Trait taxonomy: History, measurement, and theoretical perspectives. W L. A. Pervin \& O. P. John (Red.), Handbook of personality: Theory and research (2nd ed.) (s. 102-138). New York, NY, US: Guilford Press.

Kajantie, E., \& Phillips, D. I. W. (2006). The effects of sex and hormonal status on the physiological response to acute psychosocial stress. Psychoneuroendocrinology, 31(2), 151-178. https://doi.org/10.1016/j.psyneuen.2005.07.002

Kang, J.-K., \& Stulz, R. (1997). Why is there a home bias? An analysis of foreign portfolio equity ownership in Japan. Journal of Financial Economics, 46(1), 3-28. https://doi.org/doi: DOI: 10.1016/S0304-405X(97)00023-8

Kilka, M., \& Weber, M. (2000). Home Bias in International Stock Return Expectations. Journal of Psychology \& Financial Markets, 1(3-4), 176-192. https://doi.org/10.1207/S15327760JPFM0134_3

Kirschbaum, C., Pirke, K.-M., \& Hellhammer, D. H. (1993). The 'Trier Social Stress Test' A Tool for Investigating Psychobiological Stress Responses in a Laboratory Setting. Neuropsychobiology, 28(1-2), 76-81. https://doi.org/10.1159/000119004 
Kogut, B., \& Singh, H. (1988). The effect of national culture on the choice of entry mode. Journal of International Business Studies, 19(3), 411-432. https://doi.org/10.1057/palgrave.jibs.8490394

Kudielka, B. M., Hellhammer, D. H., \& Wüst, S. (2009). Why do we respond so differently? Reviewing determinants of human salivary cortisol responses to challenge. Psychoneuroendocrinology, 34(1), 2-18. https://doi.org/10.1016/j.psyneuen.2008.10.004

Kudielka, B. M., \& Kirschbaum, C. (2005). Sex differences in HPA axis responses to stress: a review. Biological Psychology, 69(1), 113-132. https://doi.org/10.1016/j.biopsycho.2004.11.009

La Porta, R., Lopez-de-Silanes, F., Shleifer, A., \& Vishny, R. (1999). The Quality of Government. Journal of Law, Economics, \& Organization, 15(1), 222-279.

Litt, A., Reich, T., Maymin, S., \& Shiv, B. (2011). Pressure and Perverse Flights to Familiarity. Psychological Science, 22(4), 523-531. https://doi.org/10.1177/0956797611400095

Lo, A. W., Repin, D. V., \& Steenbarger, B. N. (2005). Fear and Greed in Financial Markets: A Clinical Study of Day-Traders. The American Economic Review, 95(2), 352-359.

Lynn, R., \& Martin, T. (1995). National differences for thirty-seven nations in extraversion, neuroticism, psychoticism and economic, demographic and other correlates. Personality and Individual Differences, 19(3), 403-406. https://doi.org/10.1016/01918869(95)00054-A

Maner, J. K., Richey, J. A., Cromer, K., Mallott, M., Lejuez, C. W., Joiner, T. E., \& Schmidt, N. B. (2007). Dispositional anxiety and risk-avoidant decision-making. Personality and Individual Differences, 42(4), 665-675. https://doi.org/10.1016/j.paid.2006.08.016

Markowitz, H. (1952). Portfolio Selection. Journal of Finance, 7(1), 77-91. https://doi.org/10.1111/j.1540-6261.1952.tb01525.x 
Mayer, T., \& Zignago, S. (2011). Notes on CEPII's Distances Measures: The GeoDist Database. CEPII Working Paper 2011-25.

McCrae, R. R., Terracciano, A., \& 79 Members of the Personality Profiles of Cultures Project. (2005). Personality profiles of cultures: Aggregate personality traits. Journal of Personality and Social Psychology, 89(3), 407-425. https://doi.org/10.1037/00223514.89.3.407

Mosca, I., \& McCrory, C. (2016). Personality and wealth accumulation among older couples: Do dispositional characteristics pay dividends? Journal of Economic Psychology, 56(Supplement C), 1-19. https://doi.org/10.1016/j.joep.2016.04.006

Mosca, O., Lauriola, M., \& Carleton, R. N. (2016). Intolerance of Uncertainty: A Temporary Experimental Induction Procedure. PLOS ONE, 11(6), e0155130. https://doi.org/10.1371/journal.pone.0155130

Niszczota, P. (2014). Cross-country differences in personality and the foreign bias in international equity portfolios. European Journal of Finance, 20(10), 934-956. https://doi.org/10.1080/1351847X.2013.856332

Nyhus, E. K., \& Webley, P. (2001). The role of personality in household saving and borrowing behaviour. European Journal of Personality, 15(S1), S85-S103. https://doi.org/10.1002/per.422

Oberlechner, T., \& Nimgade, A. (2005). Work stress and performance among financial traders. Stress and Health, 21(5), 285-293. https://doi.org/10.1002/smi.1063

Oehler, A., Wendt, S., Wedlich, F., \& Horn, M. (2017). Investors' Personality Influences Investment Decisions: Experimental Evidence on Extraversion and Neuroticism. Journal of Behavioral Finance, O(0), 1-19. https://doi.org/10.1080/15427560.2017.1366495 
Oswald, L. M., Zandi, P., Nestadt, G., Potash, J. B., Kalaydjian, A. E., \& Wand, G. S. (2006). Relationship between Cortisol Responses to Stress and Personality. Neuropsychopharmacology, 31(7), 1583-1591. https://doi.org/10.1038/sj.npp.1301012

Paternoster, R., Brame, R., Mazerolle, P., \& Piquero, A. (1998). Using the Correct Statistical Test for the Equality of Regression Coefficients. Criminology, 36(4), 859-866. https://doi.org/10.1111/j.1745-9125.1998.tb01268.x

Preston, S. D., Buchanan, T. W., Stansfield, R. B., \& Bechara, A. (2007). Effects of anticipatory stress on decision making in a gambling task. Behavioral Neuroscience, 121(2), 257-263. https://doi.org/10.1037/0735-7044.121.2.257

Rousseeuw, P., Croux, C., Todorov, V., Ruckstuhl, A., Salibian-Barrera, M., Verbeke, T., ... Maechler, M. (2016). robustbase: Basic Robust Statistics. $R$ package version 0.92-6.

Sidanius, J., Levin, S., Liu, J., \& Pratto, F. (2000). Social dominance orientation, antiegalitarianism and the political psychology of gender: an extension and cross-cultural replication. European Journal of Social Psychology, 30(1), 41-67. https://doi.org/10.1002/(SICI)1099-0992(200001/02)30:1<41::AID-EJSP976>3.0.CO;2$\mathrm{O}$

Slovic, P., \& Peters, E. (2006). Risk Perception and Affect. Current Directions in Psychological Science, 15(6), 322-325. https://doi.org/10.1111/j.14678721.2006.00461.x

Solnik, B. H. (1974). Why Not Diversify Internationally Rather than Domestically? Financial Analysts Journal, 30(4), 48-54.

Sorokowska, A., Słowińska, A., Zbieg, A., \& Sorokowski, P. (2014). Polska adaptacja testu Ten Item Personality Inventory (TIPI) - TIPI-PL - wersja standardowa i internetowa. WrocLab. https://depot.ceon.pl//handle/123456789/5977 
Starcke, K., Wolf, O. T., Markowitsch, H. J., \& Brand, M. (2008). Anticipatory stress influences decision making under explicit risk conditions. Behavioral Neuroscience, 122(6), 1352-1360. https://doi.org/10.1037/a0013281

Stroud, L. R., Salovey, P., \& Epel, E. S. (2002). Sex differences in stress responses: social rejection versus achievement stress. Biological Psychiatry, 52(4), 318-327. https://doi.org/10.1016/S0006-3223(02)01333-1

van Hemert, D. A., van de Vijver, F. J. R., Poortinga, Y. H., \& Georgas, J. (2002). Structural and functional equivalence of the Eysenck Personality Questionnaire within and between countries. Personality and Individual Differences, 33(8), 1229-1249. https://doi.org/10.1016/S0191-8869(02)00007-7

Wilder, D., \& Simon, A. F. (2003). Affect as a Cause of Intergroup Bias. W R. Brown \& S. L. Gaertner (Red.), Blackwell Handbook of Social Psychology: Intergroup Processes (s. 153-172). Blackwell Publishers Ltd.

http://onlinelibrary.wiley.com/doi/10.1002/9780470693421.ch8/summary

Yohai, V. J. (1987). High Breakdown-Point and High Efficiency Robust Estimates for Regression. The Annals of Statistics, 15(2), 642-656.

Zobel, A., Barkow, K., Schulze-Rauschenbach, S., Von Widdern, O., Metten, M., Pfeiffer, U., ... Maier, W. (2004). High neuroticism and depressive temperament are associated with dysfunctional regulation of the hypothalamic-pituitary-adrenocortical system in healthy volunteers. Acta Psychiatrica Scandinavica, 109(5), 392-399. https://doi.org/10.1111/j.1600-0447.2004.00313.x 
Table 1. The effect of neuroticism on investment in foreign securities - results of the country-level analysis

\begin{tabular}{|c|c|c|c|c|c|c|c|c|}
\hline & \multicolumn{4}{|c|}{ Equity } & \multicolumn{4}{|c|}{ Debt } \\
\hline & \multicolumn{2}{|c|}{ NEO-PI-R } & \multicolumn{2}{|c|}{ EPQ } & \multicolumn{2}{|c|}{ NEO-PI-R } & \multicolumn{2}{|c|}{ EPQ } \\
\hline & (1) & (2) & (3) & (4) & (5) & (6) & (7) & (8) \\
\hline \multicolumn{9}{|l|}{ Home country characteristics } \\
\hline Neuroticism & $\begin{array}{c}-0.463 * * * \\
(0.071)\end{array}$ & $\begin{array}{c}-0.289 * * * \\
(0.071)\end{array}$ & $\begin{array}{c}-0.774 * * * * \\
(0.101)\end{array}$ & $\begin{array}{c}-0.638 * * * \\
(0.108)\end{array}$ & $\begin{array}{l}-0.093 \\
(0.057)\end{array}$ & $\begin{array}{l}-0.056 \\
(0.062)\end{array}$ & $\begin{array}{l}-0.102 \\
(0.073)\end{array}$ & $\begin{array}{c}-0.103 \\
(0.081)\end{array}$ \\
\hline Uncertainty avoidance & & $\begin{array}{c}-0.478 * * * \\
(0.065)\end{array}$ & & $\begin{array}{c}-0.225^{*} \\
(0.088)\end{array}$ & & $\begin{array}{l}-0.079 \\
(0.059)\end{array}$ & & $\begin{array}{c}0.001 \\
(0.066)\end{array}$ \\
\hline Home bias & $\begin{array}{c}-0.125 * * * \\
(0.038)\end{array}$ & $\begin{array}{c}-0.097 * * \\
(0.038)\end{array}$ & $\begin{array}{c}-0.318 * * * \\
(0.042)\end{array}$ & $\begin{array}{c}-0.299 * * * \\
(0.044)\end{array}$ & $\begin{array}{c}-0.208 * * * \\
(0.044)\end{array}$ & $\begin{array}{c}-0.210 * * * \\
(0.044)\end{array}$ & $\begin{array}{c}-0.222 * * * \\
(0.047)\end{array}$ & $\begin{array}{c}-0.222 * * * \\
(0.047)\end{array}$ \\
\hline GDP per capita & $\begin{array}{c}0.739 * * * \\
(0.087)\end{array}$ & $\begin{array}{c}0.634 * * * \\
(0.088)\end{array}$ & $\begin{array}{c}0.098 \\
(0.142)\end{array}$ & $\begin{array}{c}0.103 \\
(0.142)\end{array}$ & $\begin{array}{c}0.483 * * * \\
(0.091)\end{array}$ & $\begin{array}{c}0.462 * * * \\
(0.093)\end{array}$ & $\begin{array}{l}0.323^{*} \\
(0.155)\end{array}$ & $\begin{array}{l}0.325^{*} \\
(0.156)\end{array}$ \\
\hline \multicolumn{9}{|c|}{ The relationship between the home and host country } \\
\hline Geographic distance & $\begin{array}{c}-0.981 * * * \\
(0.073)\end{array}$ & $\begin{array}{c}-0.987 * * * \\
(0.073)\end{array}$ & $\begin{array}{c}-0.763 * * * \\
(0.093)\end{array}$ & $\begin{array}{c}-0.808 * * * \\
(0.094)\end{array}$ & $\begin{array}{c}-0.819 * * * \\
(0.076)\end{array}$ & $\begin{array}{c}-0.826 * * * \\
(0.075)\end{array}$ & $\begin{array}{c}-0.606 * * * \\
(0.072)\end{array}$ & $\begin{array}{c}-0.605 * * * \\
(0.075)\end{array}$ \\
\hline Trade & $\begin{array}{l}-0.021 \\
(0.074)\end{array}$ & $\begin{array}{l}-0.026 \\
(0.074)\end{array}$ & $\begin{array}{l}0.214^{*} \\
(0.100)\end{array}$ & $\begin{array}{l}0.202^{*} \\
(0.101)\end{array}$ & $\begin{array}{c}0.054 \\
(0.063)\end{array}$ & $\begin{array}{c}0.050 \\
(0.063)\end{array}$ & $\begin{array}{c}0.212 * * \\
(0.077)\end{array}$ & $\begin{array}{l}0.214 * * \\
(0.078)\end{array}$ \\
\hline Cultural distance & $\begin{array}{c}0.156^{* * *} * \\
(0.046)\end{array}$ & $\begin{array}{c}0.079 \\
(0.048)\end{array}$ & $\begin{array}{l}-0.035 \\
(0.054)\end{array}$ & $\begin{array}{l}-0.045 \\
(0.054)\end{array}$ & $\begin{array}{c}0.044 \\
(0.038)\end{array}$ & $\begin{array}{c}0.031 \\
(0.040)\end{array}$ & $\begin{array}{c}0.009 \\
(0.046)\end{array}$ & $\begin{array}{c}0.009 \\
(0.046)\end{array}$ \\
\hline Common language & $\begin{array}{c}0.960 * * * \\
(0.184)\end{array}$ & $\begin{array}{c}0.771 * * * \\
(0.182)\end{array}$ & $\begin{array}{l}0.498^{*} \\
(0.216)\end{array}$ & $\begin{array}{c}0.343 \\
(0.224)\end{array}$ & $\begin{array}{c}0.222 \\
(0.179)\end{array}$ & $\begin{array}{c}0.193 \\
(0.174)\end{array}$ & $\begin{array}{c}0.150 \\
(0.168)\end{array}$ & $\begin{array}{c}0.150 \\
(0.167)\end{array}$ \\
\hline Common religion & $\begin{array}{c}0.959 * * * \\
(0.180)\end{array}$ & $\begin{array}{c}1.024 * * * \\
(0.185)\end{array}$ & $\begin{array}{c}0.270 \\
(0.158)\end{array}$ & $\begin{array}{c}0.255 \\
(0.165)\end{array}$ & $\begin{array}{l}-0.112 \\
(0.191)\end{array}$ & $\begin{array}{l}-0.089 \\
(0.189)\end{array}$ & $\begin{array}{c}-0.649 * * * \\
(0.143)\end{array}$ & $\begin{array}{c}-0.649 * * * \\
(0.143)\end{array}$ \\
\hline Common legal origin & $\begin{array}{c}0.422 * * * \\
(0.124)\end{array}$ & $\begin{array}{c}0.187 \\
(0.127)\end{array}$ & $\begin{array}{c}0.904^{* * *} \\
(0.155)\end{array}$ & $\begin{array}{c}0.850 * * * \\
(0.156)\end{array}$ & $\begin{array}{l}-0.025 \\
(0.131)\end{array}$ & $\begin{array}{l}-0.075 \\
(0.142)\end{array}$ & $\begin{array}{c}0.457 * * * \\
(0.132)\end{array}$ & $\begin{array}{c}0.456^{* * *} \\
(0.133)\end{array}$ \\
\hline \multicolumn{9}{|l|}{ The attractiveness of the host country } \\
\hline GDP per capita & $\begin{array}{l}0.285^{*} \\
(0.141)\end{array}$ & $\begin{array}{l}0.281 * \\
(0.140)\end{array}$ & $\begin{array}{c}0.084 \\
(0.170)\end{array}$ & $\begin{array}{c}0.086 \\
(0.170)\end{array}$ & $\begin{array}{c}0.870 * * * \\
(0.156)\end{array}$ & $\begin{array}{c}0.871 * * * \\
(0.156)\end{array}$ & $\begin{array}{c}0.911 * * * \\
(0.171)\end{array}$ & $\begin{array}{c}0.911 * * * \\
(0.171)\end{array}$ \\
\hline Market capitalization to GDP & $\begin{array}{l}-0.044 \\
(0.072)\end{array}$ & $\begin{array}{l}-0.045 \\
(0.071)\end{array}$ & $\begin{array}{l}-0.025 \\
(0.079)\end{array}$ & $\begin{array}{l}-0.025 \\
(0.079)\end{array}$ & $\begin{array}{l}-0.031 \\
(0.041)\end{array}$ & $\begin{array}{l}-0.031 \\
(0.041)\end{array}$ & $\begin{array}{l}-0.030 \\
(0.050)\end{array}$ & $\begin{array}{l}-0.029 \\
(0.050)\end{array}$ \\
\hline Market volatility & $\begin{array}{c}0.089 \\
(0.072)\end{array}$ & $\begin{array}{c}0.088 \\
(0.071)\end{array}$ & $\begin{array}{c}0.088 \\
(0.092)\end{array}$ & $\begin{array}{c}0.087 \\
(0.092)\end{array}$ & $\begin{array}{c}0.010 \\
(0.088)\end{array}$ & $\begin{array}{c}0.010 \\
(0.088)\end{array}$ & $\begin{array}{c}0.076 \\
(0.102)\end{array}$ & $\begin{array}{c}0.076 \\
(0.102)\end{array}$ \\
\hline Exchange rate volatility & $\begin{array}{c}0.020 \\
(0.033)\end{array}$ & $\begin{array}{c}0.020 \\
(0.032)\end{array}$ & $\begin{array}{l}-0.015 \\
(0.041)\end{array}$ & $\begin{array}{l}-0.015 \\
(0.041)\end{array}$ & $\begin{array}{c}0.241 * * * * \\
(0.063)\end{array}$ & $\begin{array}{c}0.241 * * * \\
(0.063)\end{array}$ & $\begin{array}{c}0.236^{* *} * \\
(0.074)\end{array}$ & $\begin{array}{c}0.236 * * \\
(0.074)\end{array}$ \\
\hline Number of observations & 9541 & 9541 & 6734 & 6734 & 7821 & 7821 & 5909 & 5909 \\
\hline Adjusted $R^{2}$ & 0.193 & 0.200 & 0.241 & 0.243 & 0.316 & 0.316 & 0.426 & 0.429 \\
\hline$F$-statistic & 34.7 & 35.6 & 32.5 & 32.3 & 55.1 & 54.2 & 67.0 & 66.9 \\
\hline
\end{tabular}

Notes: This table reports random effects (GLS) panel regression results. Neuroticism levels are based on the Revised NEO Personality Inventory (NEO-PI-R) or the Eysenck Personality Questionnaire (EPQ), and are standardized. Cluster-robust standard errors are shown in parentheses. All specifications control for host country and time fixed effects.

* Significant coefficient at the $5 \%$ level; ** Significant coefficient at the $1 \%$ level; *** Significant coefficient at the $0.1 \%$ level. 
Table 2. The interaction between neuroticism and the level of similarity between countries (in the country-level analysis)

\begin{tabular}{|c|c|c|c|c|}
\hline & \multicolumn{2}{|c|}{ Equity } & \multicolumn{2}{|c|}{ Debt } \\
\hline & NEO-PI-R & EPQ & NEO-PI-R & EPQ \\
\hline \multicolumn{5}{|c|}{ Panel A. Cultural differences and trust between countries (European subsample) } \\
\hline Genetic distance & $0.053(0.180)$ & $-0.473 * *(0.168)$ & $-0.029(0.128)$ & $-0.323 * * *(0.090)$ \\
\hline Somatic distance & $0.057(0.073)$ & $-0.186 *(0.073)$ & $0.071(0.059)$ & $-0.166 *(0.066)$ \\
\hline Trust & $-0.271(0.426)$ & $0.449(0.404)$ & $-0.241(0.284)$ & $0.931 * * *(0.257)$ \\
\hline \multicolumn{5}{|c|}{ Panel B. Alternative cultural distance proxies } \\
\hline Cultural distance & $-0.033(0.055)$ & $-0.088(0.055)$ & $0.046(0.046)$ & $-0.031(0.045)$ \\
\hline Distance in language & $-0.166^{*}(0.073)$ & $-0.277 * *(0.094)$ & $-0.090(0.067)$ & $-0.155 *(0.064)$ \\
\hline Distance in religion & $-0.181 * *(0.065)$ & $0.079(0.079)$ & $-0.154 * *(0.057)$ & $-0.121 *(0.061)$ \\
\hline Distance in degree of democracy & $-0.500 * * *(0.147)$ & $-0.492 * *(0.153)$ & $0.051(0.078)$ & $-0.207 *(0.096)$ \\
\hline Distance in ideology & $-0.922 * * *(0.255)$ & $-0.473(0.281)$ & $-0.629 * *(0.214)$ & $0.072(0.232)$ \\
\hline Distance in education & $0.347 * *(0.125)$ & $0.142(0.125)$ & $-0.074(0.074)$ & $0.190 *(0.074)$ \\
\hline \multicolumn{5}{|c|}{ Panel C. Familiarity and economic distance between countries } \\
\hline Trade & $-0.004(0.042)$ & $-0.057(0.050)$ & $0.014(0.034)$ & $-0.068(0.035)$ \\
\hline Common legal origin & $0.626 * * *(0.135)$ & $0.576 * * *(0.164)$ & $0.329 * *(0.116)$ & $0.255 *(0.120)$ \\
\hline Economic distance & $0.155 * *(0.058)$ & $0.149 *(0.061)$ & $0.040(0.055)$ & $0.065(0.049)$ \\
\hline
\end{tabular}

Notes: This table reports the interaction term obtained via random effects (GLS) panel regressions. Due to a high degree of correlation between the uncertainty proxies, each pair of estimates relates to a distinct specification that assesses the interaction of neuroticism with just one uncertainty proxy. Neuroticism levels are standardized. Cluster-robust standard errors are shown in parentheses. All specifications control for host country and time fixed effects.

* Significant coefficient at the 5\% level. ** Significant coefficient at the $1 \%$ level. $* * *$ Significant coefficient at the $0.1 \%$ level. 
Table 3. The effect of variation in neuroticism on allocations in foreign stocks - results of the individual-level analysis

\begin{tabular}{|c|c|c|c|c|c|c|}
\hline & \multicolumn{3}{|c|}{ OLS } & \multicolumn{3}{|c|}{ Robust regression } \\
\hline & Full sample & Male participants & Female participants & Full sample & Male participants & Female participants \\
\hline Neuroticism & $0.001(0.005)$ & $-0.001(0.014)$ & $0.001(0.005)$ & $0.002(0.005)$ & $0.003(0.015)$ & $0.002(0.005)$ \\
\hline Neuroticism $\times$ High-anxiety condition & $0.003(0.010)$ & $-0.040^{\dagger}(0.024)$ & $0.016(0.012)$ & $-0.001(0.010)$ & $-0.047 *(0.022)$ & $0.013(0.012)$ \\
\hline High-anxiety condition & $0.039 *(0.019)$ & $0.042(0.044)$ & $0.032(0.022)$ & $0.043 *(0.019)$ & $0.046(0.041)$ & $0.035(0.022)$ \\
\hline Risk tolerance & $0.011 * *(0.003)$ & $0.008(0.011)$ & $0.012 * *(0.004)$ & $0.011^{* *}(0.004)$ & $0.010(0.011)$ & $0.012 * *(0.004)$ \\
\hline Economics major & $0.005(0.015)$ & $-0.089 *(0.040)$ & $0.026^{\dagger}(0.016)$ & $0.002(0.015)$ & $-0.118 * *(0.045)$ & $0.026(0.016)$ \\
\hline Female participant & $0.018(0.019)$ & & & $0.023(0.021)$ & & \\
\hline Number of observations & 451 & 86 & 365 & 453 & 88 & 365 \\
\hline Excluded observations & 2 & 2 & 0 & 0 & 0 & 0 \\
\hline Adjusted $R^{2}$ & 0.0183 & 0.0637 & 0.0331 & 0.0189 & 0.1090 & 0.0325 \\
\hline$F$-statistic & 2.40 & 2.16 & 3.49 & & & \\
\hline
\end{tabular}

Notes: OLS regressions are performed on a sample that that excludes two outliers (heteroscedasticity-consistent (HC3) standard errors are shown in parentheses). Robust regression results are based on the lmrob function from the robustbase package in R (Rousseeuw, Croux, Todorov, Ruckstuhl, \& Salibian-Barrera, 2016), that computes MM-type regression estimators (Yohai, 1987). $\dagger$ Significant coefficient at the $10 \%$ level. * Significant coefficient at the 5\% level. ** Significant coefficient at the $1 \%$ level. 
Fig. 1. Variation in the effect of neuroticism on investment in foreign securities
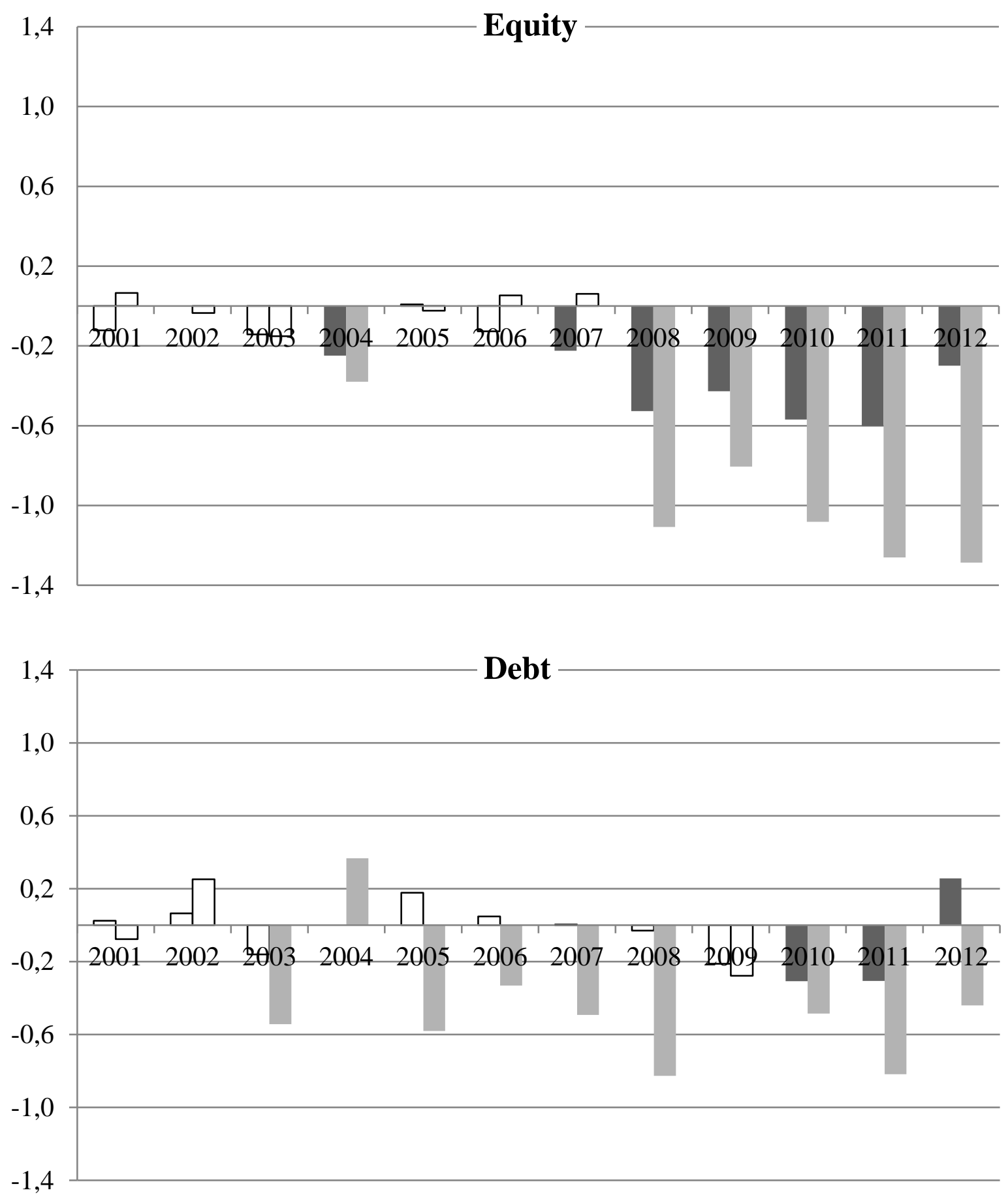

NEO-PI-R $\square$ EPQ

Notes: This figure illustrates the size of the effect of neuroticism on the level of foreign portfolio investment (after controlling for the effect of all the control variables specified in Table 1, and the host country fixed effects). Estimates are obtained via the Tobit procedure. Coefficients that are not significantly different from zero $(p \geq 0.05)$ are shown in white. 
Fig. 2. Predicted allocation in foreign stocks in the hypothetical investment problem
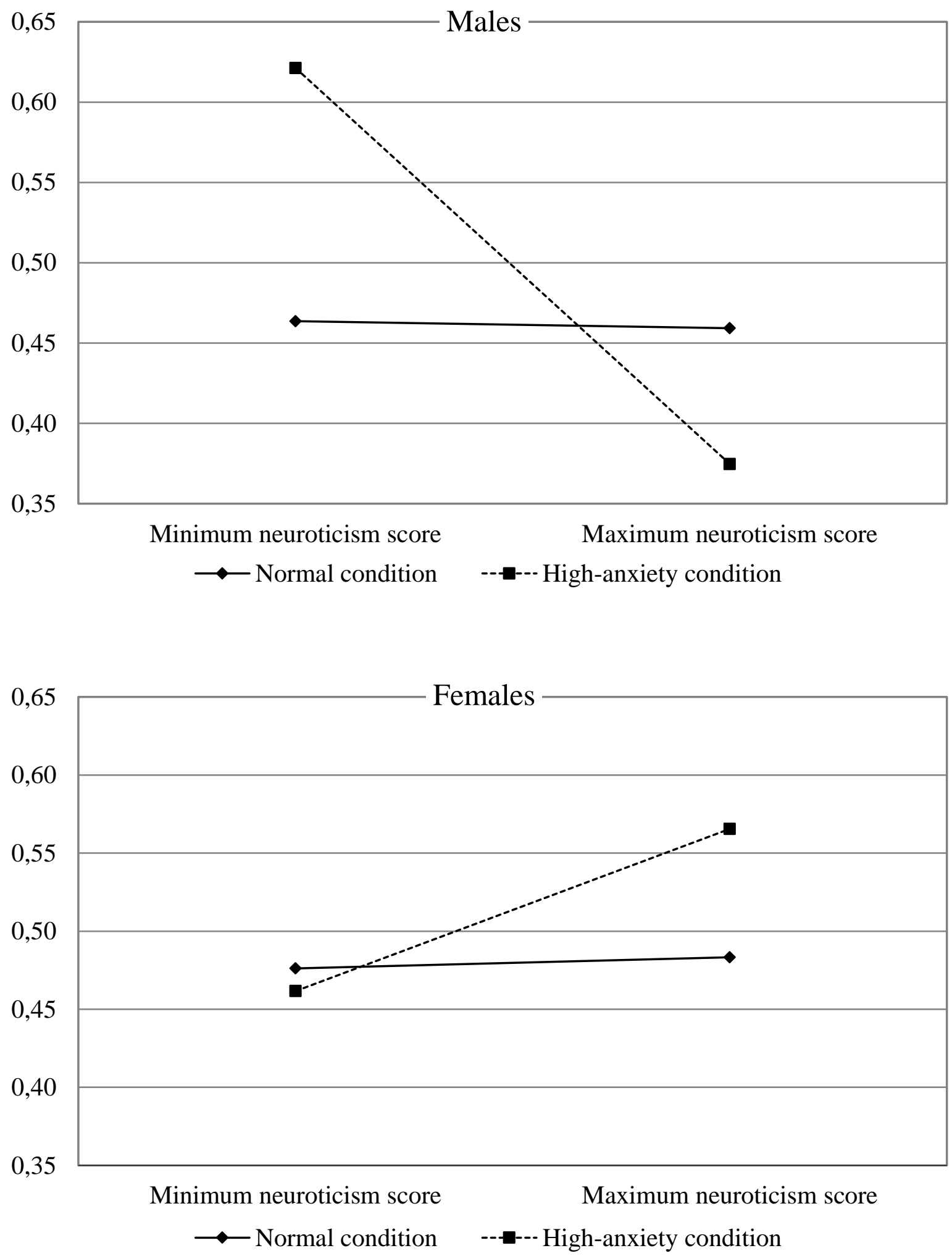

Notes: Neuroticism is scored from 1 to 7 : the average scores are lower for men $(M=3.27, S D=1.43)$ than for women $(M=4.01, S D=1.52)$. The predicted allocations are based on the OLS estimates (after excluding two outliers), with mean levels of control variables used in the computations. 


\section{Appendix}

Table A.1. Mean neuroticism scores in the home countries investigated in the countrylevel study

\begin{tabular}{lcc}
\hline Country & NEO-PI-R & EPQ \\
\hline Argentina & 51.3 & \\
Australia & 48.6 & 15.5 \\
Austria & 48.3 & \\
Belgium & 49.6 & \\
Bulgaria & & 14.9 \\
Canada & 49.6 & 12.7 \\
Chile & 50.0 & \\
Denmark & 50.3 & \\
Egypt & & 17.3 \\
Finland & & 14.6 \\
France & 52.7 & 15.1 \\
Germany & 48.1 & 13.6 \\
Hong Kong & 50.5 & 14.6 \\
Hungary & & 14.6 \\
Italy & 52.6 & 16.6 \\
Japan & 50.7 & 16.7 \\
Lithuania & & 15.1 \\
Netherlands & & 11.5 \\
Norway & & 10.3 \\
Poland & & \\
Portugal & & \\
Russia & $5.7 \%$ & $12.3 \%$ \\
Slovenia & 50.7 & 15.7 \\
South Korea & 51.6 & 18.0 \\
Spain & 51.4 & \\
Switzerland & 50.7 & 15.3 \\
Thailand & 48.4 & \\
Turkey & 49.7 & \\
United Kingdom & 50.6 & \\
United States & 48.9 & \\
\hline Mean (M) & 51.4 & \\
Standard deviation (SD) & & \\
Coefficient of variation (SD/M) & & \\
\hline
\end{tabular}

Notes: This table reports the mean neuroticism score in select countries, based on the observer-rating Revised NEO Personality Inventory (NEO-PI-R) and the Eysenck Personality Questionnaire (EPQ). 
Table A.2. The variables and datasets used in the country-level study

\begin{tabular}{|c|c|c|c|}
\hline Variable & Dataset & $\begin{array}{c}\text { Provider } \\
\text { (based on data from) }\end{array}$ & Notes \\
\hline $\begin{array}{l}\text { Equity and debt securities } \\
\text { holdings }\end{array}$ & $\begin{array}{l}\text { Coordinated Portfolio } \\
\text { Investment Survey }\end{array}$ & $\begin{array}{l}\text { International Monetary } \\
\text { Fund }\end{array}$ & \\
\hline Neuroticism & $\begin{array}{l}\text { McCrae et al., } 2005 \text { (NEO- } \\
\text { PI-R); } \\
\text { Lynn \& Martin, } 1995 \\
\text { (EPQ) }\end{array}$ & & \\
\hline Uncertainty avoidance & & & \\
\hline Cultural distance & The Hofstede Center & http://geert-hofstede.com & $\begin{array}{l}\text { Computed as in Kogut and } \\
\text { Singh (1988) }\end{array}$ \\
\hline Home bias & $\begin{array}{l}\text { Coordinated Portfolio } \\
\text { Investment Survey; } \\
\text { Debt securities statistics }\end{array}$ & $\begin{array}{l}\text { International Monetary } \\
\text { Fund; } \\
\text { Bank for International } \\
\text { Settlements }\end{array}$ & $\begin{array}{l}\text { Computed as in Fidora, } \\
\text { Fratzscher, and Thimann } \\
\text { (2007) }\end{array}$ \\
\hline $\begin{array}{l}\text { GDP per capita } \\
\text { Market capitalization to GDP } \\
\text { Economic distance }\end{array}$ & $\begin{array}{l}\text { World Development } \\
\text { Indicators }\end{array}$ & The World Bank & \\
\hline $\begin{array}{l}\text { Geographic distance } \\
\text { Common language } \\
\text { Common religion }\end{array}$ & GeoDist dataset & Mayer \& Zignano, 2011 & \\
\hline Trade & $\begin{array}{l}\text { Direction of Trade } \\
\text { Statistics }\end{array}$ & $\begin{array}{l}\text { International Monetary } \\
\text { Fund }\end{array}$ & $\begin{array}{l}\text { Computed as share of trade } \\
\text { with a given partner to the } \\
\text { total value of trade (with } \\
\text { all partners), where trade is } \\
\text { defined as the geometric } \\
\text { average of exports and } \\
\text { imports reported by both } \\
\text { trading partners }\end{array}$ \\
\hline Common legal origin & $\begin{array}{l}\text { La Porta, Lopez-de- } \\
\text { Silanes, Shleifer, \& } \\
\text { Vishny, } 1999\end{array}$ & & \\
\hline $\begin{array}{l}\text { Market volatility } \\
\text { Exchange rate volatility }\end{array}$ & Baker \& Bloom, 2013 & & \\
\hline Genetic distance & & Cavalli-Sforza et al., 1994 & \\
\hline $\begin{array}{l}\text { Somatic distance } \\
\text { Trust }\end{array}$ & Guiso et al., 2009 & $\begin{array}{l}\text { Biasutti, } 1954 \\
\text { The Eurobarometer Survey }\end{array}$ & \\
\hline $\begin{array}{l}\text { Distance in language } \\
\text { Distance in religion } \\
\text { Distance in degree of } \\
\text { democracy } \\
\text { Distance in ideology } \\
\text { Distance in education }\end{array}$ & Dow \& Karunaratna, 2006 & & \\
\hline
\end{tabular}

